\title{
Problems of Power Factor Correction in Power Supply Systems with Higher Harmonics Sources
}

\author{
Vladimir Govorun ${ }^{1}$, Oleg Govorun ${ }^{1}$, Vadim Markovskiy, ${ }^{1, *}$, and Aliya Zhumadirova $^{1}$ \\ ${ }^{1}$ NJSC Toraighyrov University, 140008 Pavlodar, Kazakhstan
}

\begin{abstract}
In this paper, on the basis of simulation modeling, an algorithm for studying the current resonance that occurs in the power supply system with a chaotic change of the load power and variation of reactive power compensation degree, in the presence of consumers with a nonlinear current-voltage characteristic is proposed. It is shown that overloading of capacitor banks can occur in a wide frequency range, close to the resonant frequency. The proposed algorithm determines all possible frequencies at which an increase of currents in capacitor banks can occur above the permissible values in parallel resonance. The purpose of the proposed work: to show in what operating modes of the enterprise power supply system an overload of capacitors by currents of higher harmonics can occur when the load power changes and the degree of reactive power compensation varies.
\end{abstract}

\section{Introduction}

One of the most actual problems of modern power supply is to improve the quality of electricity, since the consumption of electricity is significantly reducing, the reliability of power supply systems and the production process is improving.

The widespread introduction of power electronic converters into production has given rise to the problem of their negative impact on the quality of electricity. The reason for this was the nonlinear and impulsive nature of the processes of converting electricity by means of key elements that discretely control the flows of electrical energy. As a result of their operation, currents are distorted in AC circuits and, in addition to an increase of active power consumed from the network, reactive power also increases, due to the phase shift of current and voltage basic harmonics and the distortion power. For thyristor converters, the order of higher harmonics is determined by the formula $n=m k \pm 1$, where $m$ is the number of rectification phases; $k$ is a natural series of numbers.

With a 6-phase rectification circuit $\mathrm{n}=5,7,11,13$, $17,19,23,25$, etc., and with a 12-phase circuit $\mathrm{n}=11$, $13,23,25,35,37$ and etc.

The appearance of current and voltage higher harmonics in the power supply system leads to an increase of power losses, equipment overheating, insulation aging, equipment failure, etc. A fairly large number of publications are devoted to the negative influence of higher harmonics, both on individual elements of electrical equipment and on the entire power supply system [1-8].

Reactive power compensation is currently one of the priority measures in the programs being developed to increase economic efficiency in electrical power transmission and distribution.

To achieve these goals, in accordance with the law of the Republic of Kazakhstan on energy saving and improving energy efficiency, consumers of electrical energy with an attached electrical load of 630 kilovoltamperes and above are required to maintain standard power factor values on their buses by installing compensating capacitor devices.

The normative values of the power factor in electrical networks in Kazakhstan for individual entrepreneurs and legal entities are determined by the voltage class at the connection point to the electrical network:

Electric network voltage class $110-220 \mathrm{kV}>0.89$; 6 - $35 \mathrm{kV}>0.92 ; 0.4 \mathrm{kV}>0.93$.

Currently, almost all enterprises with a load above 630 kilovolt-amperes, to ensure the standard value of the power factor, as a rule, are using step-controlled capacitor units.

When power factor correction capacitors are used in a power distribution system that includes inductors and capacitors, there is always a frequency at which the capacitors are in parallel resonance with the grid. If this condition is met at the frequency of one of the harmonics generated by a non-linear energy consumer, large currents will flow between the network and the capacitor at the frequency of this harmonic, limited only by the damping resistance of the circuit. They will stack with the existing distortions, increasing them. This will result in an increase of capacitor voltage and excessive current through the system components. Overloading of capacitor banks in the CIS countries is regulated by standards [9, 10], which prohibit the operation of capacitor banks in case when the currents passing through the capacitor banks exceed the rated battery

\footnotetext{
* Corresponding author: markowski.v@,teachers.tou.edu.kz
} 
currents by 1.3 times. Abroad, according to the standard [11], the effective value of the total current passing through the capacitor bank should not exceed $135 \%$ of its rated current.

Determination of the possibility of resonant modes occurrence in power supply systems with higher harmonics sources is an urgent task, both when choosing compensating devices and when justifying the need to install filter-compensating units, therefore, in this work, another approach to assessing and solving problems arising from resonance currents is considered.

In this work, mathematical modeling of the current resonance mode will be performed when the load reactive power and the capacitance of the capacitor bank change.

The publications outline various approaches to determining the resonant frequency of a system. When calculating the mode of currents resonance, the authors of $[12,13]$ take into account the total resistance of the transformer, the capacitive conductance of cable lines and the capacitive resistance of capacitor banks, but do not take into account the complex resistance of the load.

In works [13 - 16], the authors took into account not all parameters of the electrical system. At the same time, algorithms have been created, with the help of which it is possible to determine the resonant frequencies of the power supply system when the degree of reactive power compensation changes, but without taking into account the chaotic changes in the load power.

In publications $[15-16]$, the packet wavelet transformation of the current signal is considered, which makes it possible to identify only the frequency regions at which the currents resonance condition is satisfied.

When calculating the currents resonance mode, the authors of [18] propose to take into account the total conductivity of all elements of the resonant circuit. By the expression $Z_{s y s}=R_{s y s}+j X_{s y s}$ they mean the active and inductive resistances of the elements included in the power supply system. The stated approach was developed in the proposed work.

Despite the large number of publications devoted to the study of the currents resonance, none of them [12 18] did the authors consider the problem of determining the frequency range at which capacitors overloading by currents of higher harmonics can occur when the load power changes and the stages of capacitor banks are switched. In addition, in the work, the active and reactive resistances of the resonant circuit take into account all the active, inductive and capacitive parameters of the circuits to which the capacitor bank is connected. The paper also proposes an algorithm for determining the current resonance and the frequency range at which overloading of capacitor banks can occur.

\section{Materials and methods}

At one of the enterprises, capacitor units UKRM56-6.3$2700(1350+9 \times 150)$ M4 UKHL1 with automatic reactive power regulators NOVAR 1206 were installed on both 6 $\mathrm{kV}$ buses.
After a short operation of the installations, at first on one, and then on the second installation, the fuses and cartridges of the PKT (fuse with fine-grained quartz filler for protection of power transformers and lines) type were triggered and failed.

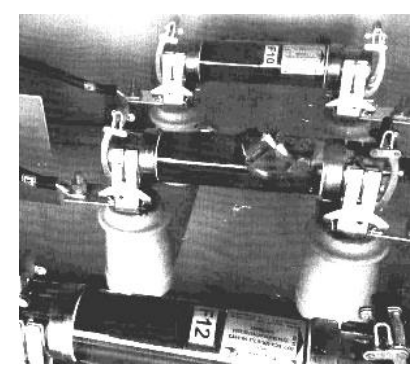

Fig. 1. Damage to the fuse and cartridge type PKT.

In an electrical network without connecting a capacitor bank, studies were carried out on the presence of harmonic distortions of the voltage curve. The results are shown in Table 1.

Table 1. Voltage harmonic distortion.

\begin{tabular}{|c|c|c|}
\hline $\begin{array}{c}\text { Harmonic's } \\
\text { number }\end{array}$ & Fixed value & $\begin{array}{c}\text { Normalized value by } \\
\text { GOST 13109-97 }\end{array}$ \\
\hline H3 & 1.0 & 3.0 \\
\hline H5 & 1.1 & 4.0 \\
\hline H7 & 5.3 & 3.0 \\
\hline H9 & 1.2 & 1.0 \\
\hline H11 & 4.1 & 2.0 \\
\hline H13 & 5.6 & 2.0 \\
\hline Total & 7.0 & 5.0 \\
\hline
\end{tabular}

It follows from the table that in the enterprise electrical network there is an excess of the permissible level of higher orders harmonic distortions, starting from the seventh harmonic, which indicates the presence in this network of a load with a nonlinear volt-ampere characteristic.

The power factor controller automatically switches the steps on and off to obtain the required reactive power values. $Q_{S C B}=(450-1350) \mathrm{kvar}$ in $150 \mathrm{kvar}$ steps.

The microprocessor regulator, by measuring the current and voltage signals, calculates the power of the capacitive load, which must be connected to the network at a given time to ensure the specified power factor.

In each step, the regulator will sequentially connect and disconnect each output. At the same time, it will measure how the connection and disconnection of a stage affects the total reactive power in the network. The condition for successful recognition of steps power is a sufficiently stable state in the network.

To assess higher harmonics effect on the operation of the UKRM56-6.3-2700 capacitor unit, specialists of UstKamenogorsk Condenser Plant LLP, together with enterprise representatives, measured the power quality indicators at the $110 / 6 \mathrm{kV}$ MSDS when changing its power.

Measurements purpose to determine the indicators of electricity quality in the supply lines of UKRM56-6.3$2700(1350+9 \times 150)$ M4 UHL1 capacitor units, as well as 


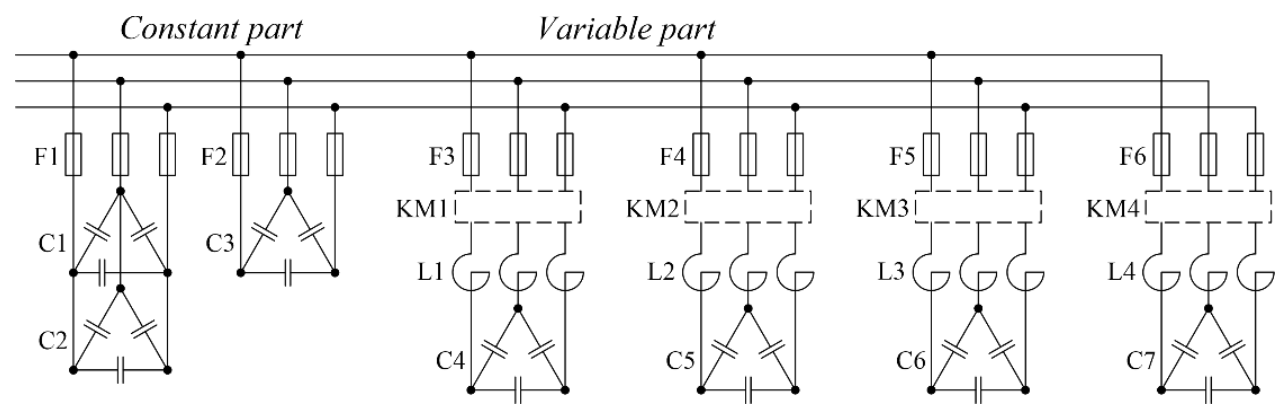

Fig. 2. Connection diagram of the UKRM-1 unit.

to determine the causes of technological disturbances during ist operation.

The measurements were carried out on two sections of switchgear $6 \mathrm{kV}$ buses with a RESURS-UF2 power quality analyzer. The analyzer was connected to the cells supplying the UKRM. Thus, the measurements reflect the indicators of electricity quality in the UKRM installations power supply circuit. In view of the previous technological violations that arose during the UKRM installations operation, and in order to avoid disruption to the well-functioning technological process of the enterprise, it was decided to turn on the installations under voltage for a period of 5-10 minutes. At the measurements time not all technological equipment was put into operation. The result of the carried out measurements is reflected in the Electric energy tests Protocols.

The analyzer was switched on at UKRM-1 at 12:23. At switching on moment the constant part of the UKRM1 - 450 kvar was already switched on. At 12:25 in the manual mode, compensation step No. 1 - 150 kvar was connected. At 12:28, step 2 is connected - 300 kvar and step 1 is disconnected - 150 kvar.

Current harmonic distortions of the UKRM-1 installation are presented in Fig. 3 and Fig. 4. The values of harmonics are displayed horizontally from 5 to 13 (harmonics below 5 are not shown because of their insignificant value). Phase $\mathrm{C}$ current harmonic distortion of the installation is approximately the same as in phase B.

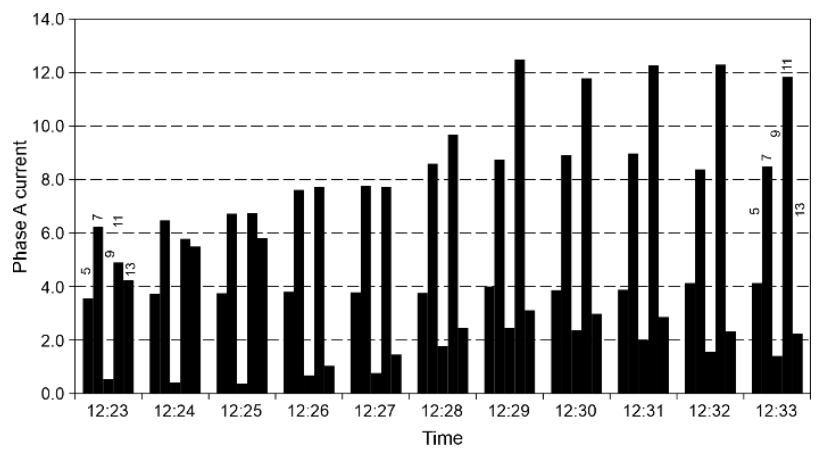

Fig. 3. Phase A current harmonic distortion.

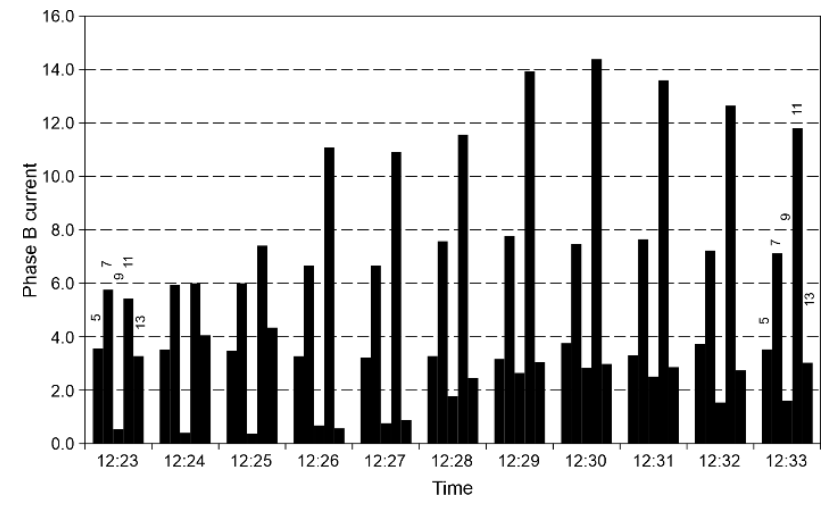

Fig. 4. Phase B current harmonic distortion.

Reactive power regulator. NOVAR 1206 installed in UKRM installations is connected to current circuits at the input to switchgear $6 \mathrm{kV}$. The distortion values recorded at the collecting buses (CB) $6 \mathrm{kV}$ input during measurements time, reflected by the controller interface, are presented in Table 2 .

From the table and figures it follows that when only the constant part 450 kvar of the capacitors is turned on, we have an overload of the current harmonic components by $7.7 \%$, that is $I_{S C B} / I_{1}=1.077$ compared to the sinusoidal harmonic current.

The greatest distortions in the UKRM-1 installation current curve occur as a result of the 7th and 11th orders current harmonics influence. After turning on the $150 \mathrm{kvar}$ step at $12: 25 \mathrm{pm}$, the current nonsinusoidality coefficient increases from approximately $6.5 \%$ ( 7 th harmonic) and $6 \%$ (11th harmonic) at $12: 24$ to $8 \%$ (7th harmonic) and 9\% (11 harmonica) at 12:26 pm. After disconnecting the $150 \mathrm{kvar}$ step and turning on the 300 kvar step at $12: 28 \mathrm{pm}$, the current nonsinusoidality factor increases from approximately $8 \%$ (7th harmonic) and 9\% (11th harmonic) at $12: 27$ to $9 \%$ (7th harmonic) and $14 \%$ (11th harmonic) at 12:29-12:30. Further experimental studies on step switching were not performed.

When the compensation steps are turned on, the distortion coefficient also increases at the input to the switchgear, which indicates the transmission of distortions to the network.

From the above, it follows that the inclusion of additional compensation steps is accompanied by an increase of the current nonsinusoidality coefficient, therefore, the current through the capacitors increases. 
Table 2. Distortion values at the $\mathrm{CB} 6 \mathrm{kV}$ input.

\begin{tabular}{|c|c|c|c|c|c|c|c|}
\hline \multirow[t]{2}{*}{ Harmonic's number } & \multicolumn{2}{|c|}{ Constant part $=450 \mathrm{kvar}$} & \multicolumn{2}{|c|}{ First step enabled - 150 kvar } & \multicolumn{2}{|c|}{ Second step enabled - 300 kvar } & \multirow[t]{2}{*}{ NTHDU } \\
\hline & THDI & THDU & THD1 & THDU & THDI & THDU & \\
\hline THD & 4.5 & 6.5 & 7.5 & 1.0 & 8.5 & 1.5 & 7.0 \\
\hline $\mathrm{H} 3$ & 0.2 & 0.6 & 0.6 & 0.2 & 0.6 & 0.1 & 1.0 \\
\hline $\mathrm{H} 5$ & 3.9 & 4.4 & 4.5 & 0.7 & 4.6 & 0.8 & 1.1 \\
\hline $\mathrm{H} 7$ & 2.3 & 3.7 & 4.6 & 0.9 & 5.4 & 1.1 & 5.3 \\
\hline $\mathrm{H} 9$ & 0.2 & 0 & 0.2 & 0.1 & 0.2 & 0.1 & 1.2 \\
\hline H11 & 0.2 & 1.2 & 2.1 & 0.5 & 4.3 & 0.7 & 4.1 \\
\hline H13 & 0.3 & 1.5 & 0.2 & 0 & 0.9 & 0.2 & 5.6 \\
\hline $\mathrm{H} 15$ & 0.1 & 0.4 & 0 & 0.2 & 0 & 0.1 & 1.4 \\
\hline H17 & 0 & 0.2 & 0 & 0.2 & 0 & 0 & 0.6 \\
\hline $\mathrm{H} 19$ & 0 & 0.2 & 0.2 & 0 & 0 & 0 & 0.4 \\
\hline CHL & & 95 & & 98 & & 100 & 132 \\
\hline
\end{tabular}

where: THD - instantaneous harmonic distortion, \%; THDI - instantaneous harmonic distortion of current, \%; THDU - instantaneous harmonic distortion of voltage, $\%$; CHL - instantaneous value of the harmonic load factor of capacitors, \%; NTHDU - maximum level of voltage harmonic distortion recorded during the period of operation, $\%$.

The maximum coefficients of non-sinusoidal current for the measurement period are fixed at 12:30 in phase B.

Consequently, the using current-limiting fuses for protection from short circuits and capacitors overloads is difficult in the presence of higher harmonic distortions in view of the possible arc re-ignition in an arc-suppression environment. This is due to the fact that, due to the surface effect caused by higher harmonics, uneven heating occurs over the cross section of the fuse-link and, consequently, to incorrect operation and failure of the fuse holders.

In view of dependence capacitors current from voltage harmonic frequencies, they are the most vulnerable power elements of modern enterprises energy infrastructure. The harmonic spectrum, obtained during measurements at the $110 / 6 \mathrm{kV}$ MSDS, is typical for the operation of rectifier units and frequency converters with six and twelve pulley rectifier circuits.

\section{Results and discussions}

Let us consider in more detail the reasons for the occurrence these reactions of power supply system to oscillations of higher harmonics and possible ways to solve them.

Active power consumption for the generation of 1 kvar reactive power is $(0.003-0.0045) \mathrm{kW}$, and active power losses in the network elements during the reactive power flow are insignificant, therefore, taking into account the active resistances of the static capacitor bank (SCB) and network total inductance is not advisable due to their smallness in compared with $X_{C}$ and $X_{H}$.

In addition, it was shown in [14] that when we determining the resonance frequency, if the active resistance in the inductive circuit of the resonant circuit is not taken into account, the error is less than $0.1 \%$. That is, when carrying out practical calculations, you can ignore the active resistance $R_{L}$.

It should be noted that active resistances in the resonant circuit have a damping effect on the amplitude of the oscillatory process.
It is known that when the capacitive and inductive resistances (conductivities) are equal, a resonance of currents occurs, at which the current in the inductance $I_{L}$ and the current in the capacitor $I_{C}$ are equal to each other. The physical essence of resonance lies in the fact that in every quarter of the sinusoid period, energy is exchanged between the magnetic field stored in the load inductance and the electric field of the capacitor bank, and the fields energy is equal to each other.

In case parallel connection of sections $g_{L O A D}, L_{L O A D}$, $C_{S C B}\left(R_{L O A D}, X_{L O A D}, X_{S C B}\right)$ the resonant frequency is determined [19]

$$
\omega_{R}=\sqrt{\frac{1}{L_{L O A D} C_{S C B}}} \quad f_{R}=\frac{1}{2 \pi \sqrt{L_{L O A D} C_{S C B}}},
$$

where $L_{L O A D}=X_{L O A D} / \omega_{0}$ - the inductance of the power supply system at the frequency of the network main harmonic; $C_{S C B}$ - capacity of a capacitor bank; $\omega_{0}=2 \pi f_{0}-$ synchronous frequency at $f_{0}=50 \mathrm{~Hz}$ frequency; $R_{L O A D}=U_{L O A D}^{2} / P_{L O A D}-$ load active resistance at base frequency; $X_{L O A D}=U_{L O A D}^{2} / Q_{L O A D}-$ load inductive reactance at base frequency; $X_{C}=1 / \omega_{0} C_{S C B}-$ inductive resistance of a capacitor bank; $P_{L O A D}, Q_{L O A D}-$ load active and reactive power, supplied to the buses, where the capacitor bank is connected; $U_{L O A D}$ - rated voltage on the buses where the SCB is connected.

It should be noted that such a representation of $R_{L O A D}$ and $X_{L O A D}$ takes into account all active, inductive and capacitive parameters of circuits connected to the buses.

Fig. 5 shows the amplitude-frequency characteristic $I_{C}(\omega), I_{L}(\omega)$ for $R, L, C$ parallel circuit, drawed under the condition that $I=$ const, $R=$ const, $L=$ const, $C=$ const [19]. 


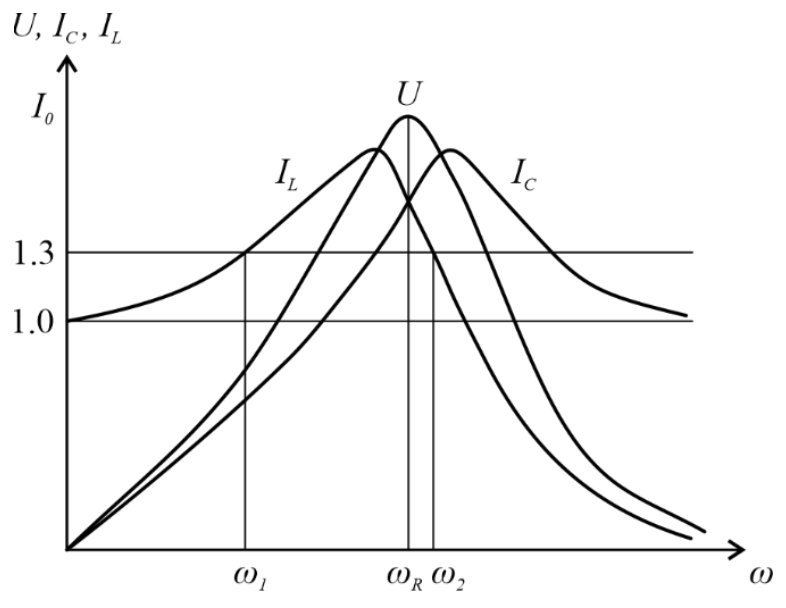

Fig. 5. Frequency response $I_{C}(\omega), I_{L}(\omega)$ for R, L, C parallel curcuit.

Frequency characteristics are drawed according to the formulas:

$$
\begin{gathered}
U(\omega)=I_{0} / \sqrt{g^{2}+(1 / \omega L-\omega C)}, \\
I_{L}(\omega)=U(\omega) / \omega L \\
I_{C}(\omega)=U(\omega) \cdot \omega C .
\end{gathered}
$$

From Fig. 5 it follows that when the oscillation frequency approaches the resonant frequency, the amplitudes of the currents harmonic components increase, and when it passes through, they fall. Consequently, capacitor banks overloading by currents exceeding the rated battery currents by 1.3 times will occur in a wide frequency band close to the resonant one.

It is obvious that the frequency band at which capacitor banks overloading the will occur lies in the range $\omega_{1}-\omega_{2}$.

The capacitor bank current depends on the resistance of the included capacitors

$$
I_{P H}=U_{P H} / X_{C},
$$

where $I_{P H}$ - capacitor phase current; $U_{P H}$ - capacitor phase voltage; $X_{C}$ - capacitors reactive resistance.

In turn, the capacitor resistance depends on the supply voltage frequency

$$
X_{C}=\frac{1}{2 \pi \cdot n \cdot C_{S C B}},
$$

where $n$ - frequency of voltage harmonic's distortion.

As can be seen from the formula, the capacitor bank resistance is inversely proportional to the supply voltage frequency, therefore, with an increase of voltage harmonic components order (an increase of the harmonic frequency), the capacitor bank resistance decreases and, therefore, the current through it at this harmonic frequency increases.

The total capacitor current is the sum of all harmonic current components geometric sum

$$
I_{S C B}=\sqrt{I_{1}^{2}+\sum_{n \geq 2} I_{n}}
$$

Overcurrent can be determined by the equation

$$
\begin{aligned}
& \frac{I_{S C B}}{I_{1}}=\sqrt{1+\left(u_{3} \cdot 3\right)^{2}+\left(u_{5} \cdot 5\right)^{2}+\left(u_{7} \cdot 7\right)^{2}+\cdots+} \\
& \overline{+\left(u_{15} \cdot 15\right)^{2}+\left(u_{17} \cdot 17\right)^{2}+\left(u_{19} \cdot 19\right)^{2}+\cdots},
\end{aligned}
$$

where $I_{1}$ - effective value of the base (first) harmonic's current; $I_{N}$ - effective value of the n-th harmonic's current, $u_{i}$ - instantaneous level of voltage harmonic distortion, $\%$.

Consequently, the SCB overload and the fuses failure can occur in a wide frequency range, close to the resonant one. It also depends on the peak amplitudes of harmonic distortions and their phase shifts to each other, created by different sources of harmonics.

The use of capacitor units in such network operating modes is impossible, since they will operate with a significant current overload, which in a sufficiently short period of time will lead to additional capacitor banks heating and destruction or fuses failure.

It should be noted that during enterprise operation the load for technological reasons (on / off) or emergency shutdowns can change in a very wide range, provided that the number of connected capacitors remains unchanged due to the inertia of the SCB regulator. Therefore, studying the current resonance, it is necessary to carry out calculations of all possible modes of network operation.

It is not difficult to use the method proposed above to determine the frequency range at which the capacitor bank will overload when the load power and the number of capacitor banks change. Required to build dependencies $U(\omega), I_{C}(\omega), I_{L}(\omega)$ for the four cases:

- minimum load and minimum number of connected capacitors;

- minimum load and maximum number of connected capacitors;

- maximum load and minimum number of connected capacitors;

- maximum load and maximum number of connected capacitors.

Based on the constructed dependences, it is possible to carry out a complete analysis of the possibility of current resonance occurrence and capacitors overloading with a wide change in the load power and the number of connected capacitor banks.

Let's consider another approach to solving the problem.

Fig. 6 shows a graph of reactive power average change in load and capacitor bank. In this case, the value of the power factor lies in the range of $0.92-0.93$. 


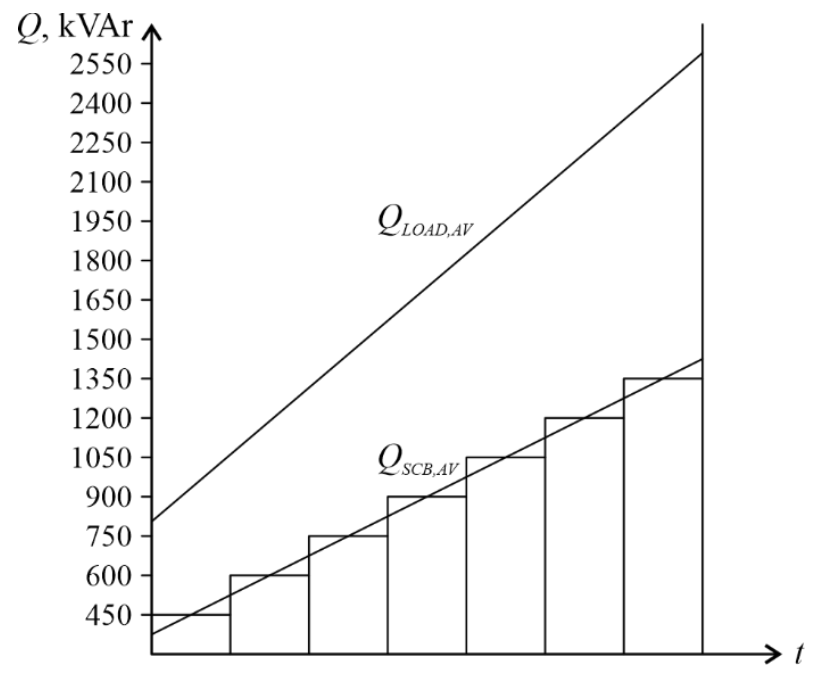

Fig. 6. Graph of changes in the average power of the SCB and the reactive power of the load.

Based on the known minimum and maximum load power, we determine inductive resistances values at the fundamental harmonic

$$
\begin{aligned}
& X_{L 1}=U_{L O A D}^{2} / Q_{L O A D \min }, \\
& X_{L 2}=U_{L O A D}^{2} / Q_{L O A D \max } .
\end{aligned}
$$

Then we calculate the inductance at the same frequency

$$
\begin{aligned}
& L_{1}=X_{L 1} / 2 \pi \cdot f_{0}, \\
& L_{2}=X_{L 2} / 2 \pi \cdot f_{0} .
\end{aligned}
$$

Using the found values $L_{1}$ and $L_{2}$ determining $X_{L 1}$ and $X_{L 2}$ at other frequencies by the formula

$$
X_{L i}=2 \pi \cdot f_{0} \cdot n \cdot L_{i},
$$

where $n$ is the harmonic's number.

Building dependencies $X_{L 1}(\omega)$ and $X_{L 2}(\omega)$ for maximum and minimum load.

Similarly, we perform calculations for the minimum and maximum capacitance values of the SCB using the formulas

$$
\begin{gathered}
X_{C 1}=U_{L O A D}^{2} / Q_{S C B \min }, \\
X_{C 2}=U_{L O A D}^{2} / Q_{S C B \max }, \\
C_{1}=X_{C 1} / 2 \pi \cdot f_{0}, \\
C_{2}=X_{C 2} / 2 \pi \cdot f_{0}, \\
X_{C i}=2 \pi \cdot f_{0} \cdot n \cdot C_{i} .
\end{gathered}
$$

Building dependencies $X_{C 1}(\omega)$ and $X_{C 2}(\omega)$ for maximum and minimum SCB capacitance value.
Fig. 7 shows the dependencies $X_{L 1}(f), X_{L 2}(f)$, $X_{C 1}(f), X_{C 2}(f), X_{L 1}(f)+X_{C 1}(f), X_{L 2}(f)+X_{C 1}(f)$, $X_{L 1}(f)+X_{C 2}(f), X_{L 2}(f)+X_{C 2}(f)$.

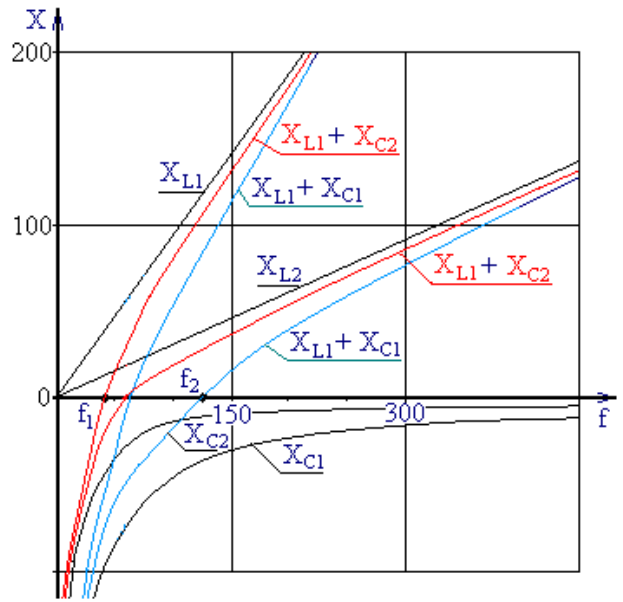

Fig. 7. Dependecies $X_{L 1}(f), X_{L 2}(f), X_{C 1}(f), X_{C 2}(f)$.

From the dependencies plotted in Fig. 7, it is also possible to carry out a complete analysis of the possibility of current resonance occurrence with a wide change in the load power and the number of connected capacitor banks. The resonance frequency is determined from the condition

$$
X_{L 2}(f)+X_{C 2}(f)=0 .
$$

The figure shows that current resonance can occur in a wide frequency range $\left(f_{1}-f_{2}\right)$ with a possible change in the load and SCB capacitance.

Additional devices are used to reduce the amplitudes of higher harmonics caused by non-linear loads. Sometimes it is sufficient to connect a harmonic filter in series with the capacitor so that the filter / capacitor circuit is inductive at the critical frequencies and capacitive at the fundamental frequency. For this, the series-connected capacitor and filter circuit must have a natural frequency below the lowest critical harmonic. The frequency value depends on the amplitudes and the order of the harmonics present.

Installing a harmonic filter increases the voltage across the capacitor, and the potential for voltage resonance appears. This must be taken into account when installing a harmonic filter in a capacitor bank.

The most commonly used method of protecting the SCB from the negative action of higher harmonics is to connect damping reactor in series with capacitance fig. 8 [20].

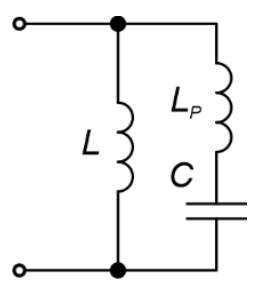

Fig. 8. The reactor is connected in series with the capacitor. 
When reactive shunt is connected in series with capacitance, the expression for the input resistance has the form

$$
\begin{gathered}
X_{\Sigma}(\omega)=\frac{j \omega L \cdot 1 / j \omega C+j \omega L j \omega L_{P}}{j \omega L_{P}+j \omega L+1 / j \omega C}= \\
=\frac{j \omega L-\omega^{3} L L_{1} C}{-\omega^{2} C L_{1}-\omega^{2} L C+1}=\frac{A(\omega)}{B(\omega)} .
\end{gathered}
$$

By $A(\omega)=0, j \omega L-\omega^{3} L L_{P} C=0$ we are getting the frequency $\omega_{R 1}=\sqrt{\frac{1}{L_{P} C}}$ corresponding to the voltages resonance, and at $B(\omega)=0$ from solving the equation $\omega^{2} C\left(L_{P}+L\right)-1=0 \quad \omega_{R 2}=\sqrt{\frac{1}{C\left(L_{P}+L\right)}} \quad$ frequency, corresponding to the currents resonance.

In some cases, to protect the SCB from the negative action of higher harmonics, also use reactors switched on in series with capacitors and load on fig. 9 [20].

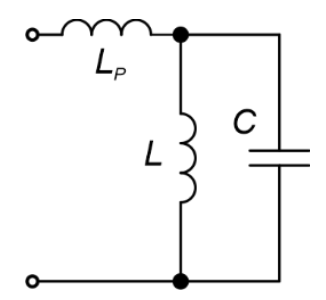

Fig. 9. The reactor is connected in series with the capacity and load.

Let us determine the resonant frequencies for circuits with a series-connected reactor. When reactor is connected in series with the load, the expression for the input resistance has the form

$$
\begin{gathered}
X_{\Sigma}(\omega)=j \omega L_{P}+\frac{j \omega L}{1-\omega^{2} L C}= \\
=\frac{j \omega L_{P}-\omega^{3} L_{P} L C+j \omega L}{1-\omega^{2} L C}=\frac{A(\omega)}{B(\omega)_{\Sigma}} .
\end{gathered}
$$

By $A(\omega)=0$ we are getting a frequency $\omega_{R 1}=\sqrt{\frac{L_{P}+L}{L_{P} L C}}$ corresponding to the voltages resonance, and at $B(\omega)=0$ from solving the equation $1-\omega^{2} L C$ $\omega_{R 2}=\sqrt{1 / L C}$ frequency, corresponding to the currents resonance.

\section{Conclusion}

During enterprise operation the load for technological reasons (on / off) or emergency shutdowns can vary in a very wide range, provided that the number of connected capacitors remains unchanged due to the inertia of the SCB regulator. Therefore, studying the current resonance, it is necessary to carry out calculations of all possible modes of network operation.

Active resistances in the resonant circuit have only a damping effect on the oscillatory process amplitude, and does not affect the resonant frequency, since resonance occurs only when the magnetic and electrical energies are equal.

Capacitors overloading can also occur at frequencies above or below the resonant frequency and depends on the amplitudes of the frequency spectrum coming from the harmonic source.

Based on the algorithms proposed in the work, it is possible to determine the frequency range at which the current resonance condition will be satisfied, as well as to conduct a full analysis of the possibility of capacitor overloading with a wide change in the load power and the number of connected capacitor banks.

Determination of the frequency range at which the capacitors overload will occur is necessary for the methods and means of suppressing higher harmonics selection, the selection and adjustment of devices designed to reduce the higher harmonic currents amplitudes in the network.

When the reactor is connected in series with the capacitor, in addition to increasing the voltage across the capacitor, the possibility of voltage resonance may appear. This must be taken into account when installing a harmonic filter in a capacitor bank.

\section{References}

1. Rukovodstvo po kompensatsii reaktivnoi moshchnosti s uchetom vliyaniya garmonik, Schneider Electric, 21, 26 (2008)

2. Garmonicheskie iskazheniya v elektricheskikh setyakh i ikh snizhenie, Schneider Electric, 22, 28 (2008)

3. I. Zhezhelenko, Vysshie garmoniki $v$ setyakh elektrosnabzheniya promyshlennykh predpriyatii (Energoatomizdat, 331, 2000)

4. IEEE Recommended practice for monitoring electric power quality, IEEE Std, 1159-1995 (1995) DOI: $10.1109 /$ IEEESTD.1995.79050

5. A. Kusko, M. Thompson, Power Quality in Electrical Systems (McGraw-Hill Education, 2007)

6. R. Stratford, Analysis and control of harmonic current in systems with static power converters, IEEE Transactions on Industry Applications, IA17, 71-81 (1981) DOI: 10.1109/tia.1981.4503902

7. H. Akagi, Active harmonic filters, Proceedings of the IEEE, 93, 2128-2140 (2005) DOI: 10.1109/JPROC.2005.859603

8. V. Govorun, O. Govorun, B. Shapkenov, V. Markovskii, Yu. Icheva, S. Ramazanov, Povyshenie effektivnosti peredachi elektricheskoi energii, Vestnik PGU, 1, 139-149 (2020)

1. 9. Kondensatornye ustanovki kompensatsii reaktivnoi moshchnosti [Electronic resource] Available at: http://www.kondensator.su/kondensatornye- 
ustanovki/krm-reactive-power-compensation.html (accessed: 10.11.2020)

10. Ustanovki kompensatsii reaktivnoi moshchnosti [Electronic resource] Available at: https://profsector.com/publication/1/ustanovkikompensatsii-reaktivnoy-moshhnosti (accessed: 10.11.2020)

11. IEEE Standard for Shunt Power Capacitors [Electronic resource], IEEE Std, 18-2012, 69 (2013) Available at: https://ieeexplore.ieee.org/servlet/opac?punumber $=6484082$

12. A. Nikolaev, G. Kornilov, T. Khramshin, G. Nikiforov, F. Mutallapova, Eksperimental'nye issledovaniya elektromagnitnoi sovmestimosti sovremennykh elektroprivodov $\mathrm{V}$ sisteme elektrosnabzheniya metallurgicheskogo predpriyatiya, Vestnik MGTU im. G. I. Nosova, 4, 96-105 (2016)

13. V. Petukhov, I. Krasilov, Rezonansnye yavleniya $\mathrm{v}$ elektroustanovkakh zdanii kak faktor snizheniya kachestva elektroenergii [Electronic resource], Novosti elektrotekhniki, 6 (24) (2003) Available at: http://www.news.elteh.ru/arh/2003/24/20.php (accessed: 05.11.2020)

14. D. Kovalenko, Opredelenie rezonansnoi chastoty sistemy elektrosnabzheniya pri izmenenii stepeni kompensatsii reaktivnoi moshchnosti i nalichii vysshikh garmonik [Electronic resource], Mezhdunarodnyi zhurnal prikladnykh i fundamental'nykh issledovanii, 8, 16-21 (2017) Available at: http://www.appliedresearch.ru/pdf/2017/8-1/11751.pdf (accessed: 15.11.2020)

15. D. Osipov, D. Kovalenko, N. Dolgikh, Calculation of currents resonance at higher harmonics in power supply systems based on wavelet packet transform, Dynamics of Systems, Mechanisms and Machines (Dynamics), 1-6 (2017) DOI: 10.1109/Dynamics.2017.8239492

16. L. Faifer, D. Osipov, E. Eremin, N. Dolgikh, Primenenie paketnogo veivlet-preobrazovaniya dlya opredeleniya sostavlyayushchikh moshchnosti pri nesinusoidal'nykh rezhimakh, Vestnik Irkutskogo gosudarstvennogo tekhnicheskogo universiteta, 8 (115), 136-145 (2016)

17. S. Siromakha, D. Osipov, V. Cheremisin, O neobkhodimosti ucheta rezhima raboty i impedansa sistemy elektrosnabzheniya pri modelirovanii rezonansa tokov [Electronic resource], Sovremennye problemy nauki i obrazovaniya, 5 (2014) Available at: http://www.science-

education.ru/ru/article/view?id=15252 (accessed: 15.11.2020)

18. S. Rahimi, W. Wiechowski, M. Rundrup, J. Ostergaard, A.H. Nielsen, Identification of problems when using long high voltage AC cable in transmission system II: Resonance \& Harmonic resonance, 2008 IEEE/PES
Transmission and Distribution Conference and Exposition, $\quad 1-8 \quad$ (2008) DOI: 10.1109/TDC.2008.4517187

19. A. Neiman, K. Dimirchyan, Teoreticheskie osnovy elektrotekhniki (Energoizdat, Leningradskoe otdelenie, 535, 1981)

20. S. Smirnov, Vysshie garmoniki $v$ setyakh vysokogo napryazheniya (Nauka, 327, 2010) 